\title{
OS SENTIDOS DE CURRÍCULO E A CONFIguRAÇÃo da PRÁtica PEDAgógica
}

\begin{tabular}{r}
\hline CURRICULUM SENSES AND CONFIGURATION OF PEDAGOGICAL PRACTICE \\
\hline LOS SENTIDOS DEL CURRÍCULO Y LA CONFIGURACIÓN DE LA PRÁCTICA PEDAGÓGICA \\
\hline \\
Maria Narleide Oliveira Castro $^{1}$ \\
Edinaldo Medeiros Carmo $^{2}$
\end{tabular}

RESUMO: Este estudo tem como foco os sentidos que professoras atribuem ao currículo escolar e o papel docente em seu desenvolvimento. Trata-se de uma pesquisa de natureza qualitativa, realizada com quatro docentes em uma escola pública de Vitória da Conquista, Bahia. A entrevista semiestruturada foi o meio para produção dos dados, os quais foram analisados por meio da Análise de Conteúdo. Os resultados mostram que o currículo é compreendido como um instrumento de grande relevância no trabalho docente e na formação discente e objetiva educar para a vida, preparar para as avaliações externas e para o trabalho. Desse modo, o docente é visto como mediador entre o currículo e os alunos e principal agente em seu desenvolvimento na escola.

PALAVRAS-ChAVE: Currículo escolar. Avaliações externas. Professor mediador.

ABSTRACT: This study focuses on meanings that teachers attribute to school curriculum and teaching role in their development. It is a qualitative research carried out with four teachers in a public school in Vitória da Conquista, Bahia. The semi-structured interview has been the means for producing data, which have been analyzed through content analysis. The results show that the curriculum is understood as an instrument of great relevance in teaching work and in student training and it objectives to educate for life, prepare for external evaluations and for work. In that sense, teacher is seen as a mediator between curriculum and students and the main agent in its development in the school.

KEYWORDS: School curriculum. External evaluations. Mediator teacher.

RESUMEN: El foco de este estudio es el sentido que las profesoras le atribuyen al currículo escolar y al papel docente en su desarrollo. Se trata de una investigación de naturaleza cualitativa, realizada con cuatro docentes en una escuela pública de Vitória da Conquista, Bahía. La entrevista semiestructurada fue el instrumento utilizado para producir los datos, los cuales fueron analizados por medio del estudio de su contenido. Los resultados muestran que el currículo se entiende como un instrumento de gran relevancia en el trabajo docente y en la formación discente y que objetiva educar para la vida, preparar para las evaluaciones externas y para el trabajo. De ese modo, se ve al docente como mediador entre el currículo y los alumnos y como agente principal de su desarrollo en la escuela.

PALABRAS CLAVE: Currículo escolar. Evaluaciones externas. Profesor mediador.

\footnotetext{
${ }^{1}$ Submetido em: 17/11/2017 - Aceito em: 02/04/2018 - Publicado em: 20/11/2018
}

\begin{tabular}{l|l|l|l|l|l|l} 
(C) Rev. Educ. Perspec. & Viçosa, $M G$ & v.9 & n.2 & p.259-274 & maio/ago. 2018 & eISSN 2178-8359 \\
\hline
\end{tabular}




\section{INTRODUÇÃO}

Os diversos estudos sobre a temática curricular demonstram que o conhecimento presente no currículo não é algo imutável e fixo. Pelo contrário, de acordo com Silva (1999), ele está em constante fluxo e transformação. Logo, seu desenvolvimento está associado ao da sociedade, ou seja, a história do currículo e a história geral da educação estão interligadas, e o valor da escola se manifesta primordialmente pelo que ela faz ao desenvolver um determinado currículo (SACRISTÁN, 2000). Por este motivo, é importante compreendê-lo, já que ele é o eixo orientador que dá sentido a toda ação educativa. Assim, a clareza daquilo que se faz e como se faz torna-se um pressuposto para uma prática docente responsável, comprometida e ética.

Desse modo, vale salientar que a definição de currículo não é algo tão simples, pois inúmeras pesquisas apontam para a polissemia do termo. Acreditamos que os diferentes sentidos atribuídos ao currículo resultam em práticas pedagógicas originadas por meio de diferentes formas de compreendê-lo. A esse respeito, Moreira e Candau (2007) relacionam as inúmeras definições curriculares às várias maneiras de entender a educação, bem como às influências teóricas, socioeconômicas, políticas e culturais, que acabam determinando o significado à ele atribuído. Dessa forma, considerando que o currículo se materializa no ensino, no momento em que alunos e professores vivenciam experiências nas quais constroem e reconstroem conhecimentos e saberes, é possível perceber a relevância do currículo como objeto de estudo (MOREIRA, 2013).

Nesse sentido, conhecer o que pensam os professores, como agem, porque tomam determinadas decisões, como resolvem os dilemas da prática educacional por meio de suas teorias implícitas e de suas histórias, nos permite evidenciar a importância do estudo do currículo a partir da perspectiva docente, pois ele é um profissional que, com base em suas experiências e formação, continuamente, tem que decidir e atribuir valor aos efeitos causados por meio da sua ação. Portanto, os professores são profissionais cujas competências ampliamse à medida que o contexto da prática exige e ao mesmo tempo contribui para isso, pois o que é ensinado na escola é uma reinterpretação de conhecimentos e saberes disponíveis na cultura, considerados valiosos pela sociedade (ACOSTA, 2013).

Sendo assim, os sentidos que os professores atribuem ao currículo são relevantes, pois influenciam suas práticas pedagógicas e, consequentemente, a formação dos educandos. Em função disso, concordamos com Moreira e Candau (2007) ao defenderem que não há dúvidas quanto à importância do currículo no processo educativo, pois ele é o coração da escola, é por meio dele que tudo acontece e é nele que são sistematizados todos os esforços pedagógicos. Devido à relevância dessa discussão acerca da questão curricular e do papel decisivo a ser

\begin{tabular}{l|l} 
Viçosa, $M G$ & v.9
\end{tabular}

n.2 2 p.259-274

maio/ago. 2018

eISSN 2178-8359


desenvolvido pelo docente na materialização do currículo, reiteramos a importância de que as prescrições curriculares não sejam vistas como inquestionáveis e os docentes como meros executores das mesmas. Visto que, mesmo não tendo consciência, o professor é um dos atores mais importantes no desenvolvimento do currículo, a quem cabe traduzir a proposta curricular da escola em ações educativas que conduzam os alunos no processo de aprendizagem.

Diante do exposto, realizamos este estudo com o objetivo de analisar os sentidos que os docentes atribuem ao currículo escolar e evidenciar o papel do professor no seu desenvolvimento. Trata-se de uma pesquisa de natureza qualitativa, realizada em uma escola pública do município de Vitória da Conquista, Bahia, tendo como sujeitos quatro professoras ${ }^{1}$ de diferentes áreas de formação e atuação profissional, que tinham entre 13 e 26 anos de exercício docente, as quais foram selecionadas por serem efetivas, lecionarem no Ensino Médio e por concordarem em contribuir com a pesquisa. A entrevista semiestruturada foi utilizada para produção das informações, as quais foram analisadas por meio da Análise de Conteúdo, realizada em três etapas: pré-análise, exploração do material e tratamento dos resultados e, por fim, inferência e interpretação. Desse modo, como resultado desse trabalho interpretativo, os dados aqui apresentados foram organizados em três categorias, a saber: Currículo escolar: um conceito polissêmico; currículo do Ensino Médio: finalidades e imperativos avaliativos; e papel do professor no desenvolvimento do currículo.

\section{CURRÍCULO ESCOLAR: UM CONCEITO POLISSÊMICO}

Esta categoria apresenta os sentidos que as professoras atribuem ao currículo, já que esse é um processo influenciado por diversos fatores $\mathrm{e}$ que tem particular impacto no desenvolvimento da ação pedagógica. Logo, abordar o que é significativo para cada docente é, de certa forma, revelar as razões que subsidiam as suas ações enquanto professoras, pois elas possuem significados que são construídos durante a formação, no entanto, outros resultam de suas experiências difusas sobre diversos aspectos do currículo, tais como: conteúdos, habilidades, orientações metodológicas, avaliações etc (SACRISTÁN, 2000).

Inicialmente, julgamos pertinente situar, neste trabalho, o sentido que estamos atribuindo ao currículo, o qual é defendido por Sacristán (2000) como um processo que se configura na prática. Portanto, o trabalho desse autor se fundamenta numa abordagem prática da questão curricular, o meio pelo qual o currículo se transforma na prática pedagógica.

Ademais, convém salientar que este trabalho se assenta na perspectiva crítica de currículo, pois, segundo Sacristán (2000, p. 21), 
O currículo modela-se dentro de um sistema escolar concreto, dirige-se a determinados professores e alunos, serve-se de determinados meios, cristaliza, enfim, num contexto, que é o que acaba por lhe dar o significado real. Daí a única teoria possível que possa dar conta desses processos tenha de ser do tipo crítico, pondo em evidência as realidades que o condicionam.

Essas teorias, segundo Malta (2013), enfatizavam o significado subjetivo que era atribuído às experiências pedagógicas e curriculares de cada indivíduo, as quais eram analisadas a partir de uma perspectiva profundamente subjetiva, e também os processos pelos quais professores e alunos desenvolviam seus significados acerca do conhecimento.

Os resultados ratificam a amplitude do termo currículo e a sua polissemia foi percebida nos depoimentos das entrevistadas. A professora Telma o define como percurso de formação do aluno e sua construção é fundamental para que o processo educativo tenha coerência, coesão e, realmente, consiga alcançar objetivos que estejam em consonância com o que é proposto para a formação do aluno. Nesse relato, notamos que o sentido atribuído ao currículo está atrelado à ideia de caminho a ser seguido e que possui grande importância no processo formativo. Do mesmo modo, Moreira e Candau (2007) defendem que é no currículo, e por meio dele, que tudo acontece na escola, justificando sua relevância na formação do aluno. Para os autores, os diversos significados atribuídos ao currículo resultam dos divergentes posicionamentos, compromissos e pontos de vista teóricos, e o associam a um conjunto de esforços pedagógicos realizados com fins educativos, que colaboram para a construção das identidades dos educandos. Ademais, Moreira (2012, p. 735) destaca a necessidade de redefinir o "[...] currículo como instituinte de sentidos, como enunciação da cultura, como espaço indecidível em que os sujeitos se tornam sujeitos por meio de atos de criação [...]”, os quais são realizados pelos professores e auxiliam o processo de formação dos educandos.

Outro sentido que emerge das narrativas é o da professora Suely, para quem o currículo escolar significa "[...] o conjunto de disciplinas, conteúdos, metodologia. [...] são as opções que a escola faz". Ao analisar o sentido atribuído por essa professora, julgamos pertinente ressaltar que o currículo não é apenas uma relação de conteúdos que devem ser aprendidos pelos alunos, envolve todo o processo educativo, ao mesmo tempo em que é a diretriz do trabalho a ser desenvolvido pelo educador. Conforme destaca Silva (1999), nas discussões cotidianas, o currículo é relacionado apenas ao conhecimento, desprezando-se que o conhecimento que o constitui está intimamente envolvido naquilo que somos e que nos tornamos: na nossa identidade e subjetividade. Nesse contexto, importa destacar a perspectiva apresentada por Albino, Pereira e Lima (2014, p. 2) na qual defendem o currículo como um espaço de produção cultural, bem como de produção de sujeitos singulares, além de ser "[...] um território em disputa, fruto de relações de poder, articulado a um modelo de homem e cultura almejados, temporalmente, no espaço social”. 
Por sua vez, a professora Ecy atribui ao currículo o sentido de instrumento direcionador que, deve estar em sintonia com o Projeto Político Pedagógico da escola. Ela afirma: "[...] é um norte, a gente começa com esse norte, mas ele sofre muitas modificações, não é engessado, não é rígido, é flexível, justamente devido a essas adaptações que a gente faz e pelo público que é muito diversificado".

Contrariamente às demais colegas, Conceição atribui um sentido de currículo ainda circunscrito, ela o considera como "Falho! Na verdade, não é uma questão de ser falho, vou falar da minha área [matemática]. A gente tem uma carga horária e a questão dos conteúdos não conseguimos atingir". Acreditamos que esse sentido limitado atribuído pela docente está intimamente relacionado às condições de trabalho docente, em especial, ao descompasso existente entre a carga horária e a quantidade de conteúdos da disciplina que ministra, o que a impossibilita de cumprir satisfatoriamente o seu planejamento. Em função disso, ressaltamos que é necessário evitar que o ensino de conteúdos seja a única meta da escola (SACRISTÁN, 2013), uma vez que, de acordo com Vasconcelos (2007, p. 186), “[...] a tarefa fundamental do professor não é cumprir o programa, mas ajudar o educando a desenvolver-se e compreender a realidade, sendo o programa um meio para isto e não um fim em si mesmo".

Esse mesmo problema de inadequação da quantidade de conteúdos com a carga horária da disciplina foi mencionado pela professora Suely. Depreendemos desses relatos o sentido de currículo como programa a ser cumprido, uma visão recorrente quando se discute a questão curricular. Conforme destacado por Moreira e Candau (2007), o currículo, muitas vezes, é entendido como os conteúdos a serem ensinados e aprendidos. Esse entendimento se aproxima da visão tradicional de currículo, o qual " [...] era concebido como uma questão simplesmente técnica, pois se resumia em discutir as melhores e mais eficientes formas de organizá-lo" (MALTA, 2013, p. 339).

Diante do exposto, os resultados sinalizam para sentidos de currículo enquanto ferramenta de fundamental importância no processo educativo, no entanto, também é visto de modo circunscrito, tendo sua relevância reduzida. Essas ponderações caracterizam a polissemia de conceitos que circunscrevem o currículo escolar, que, para Sacristán (1998a), pode indicar riqueza, por ainda estar em fase de elaboração conceitual, oferecendo perspectivas distintas sobre a realidade do ensino. Dessa forma, acreditamos que os diferentes significados atribuídos ao currículo sejam frutos da forma como cada professora vivencia e interpreta a realidade, pois a história e a trajetória profissional de cada uma fazem com que tenham visões distintas do currículo, ainda que inseridas no mesmo contexto educativo. 


\section{CURRÍCULO DO ENSINO MÉDIO: FINALIDADES E IMPERATIVOS AVALIATIVOS}

Com base nos sentidos atribuídos pelas professoras ao currículo, indagamos sobre as finalidades do currículo no processo educativo. Segundo Sacristán (1998b), o ensino sempre tem uma intencionalidade e persegue determinados ideais, portanto, é uma ação dirigida para algum fim. Essas ações de ensino são significativas, pois tanto dependem das intenções dos sujeitos, quanto dos significados atribuídos por eles (CONTRERAS, 2002). Desse modo, o currículo, como elemento central e indispensável ao trabalho docente, possui significativo papel no percurso formativo do aluno. Além disso, ele contribui para construção do que somos e até do que não somos (BARG, 2012). Sendo assim, é imprescindível refletir sobre o significado que tem sido atribuído ao currículo no processo educativo, sobretudo, pelos professores, que são os responsáveis diretos por sua materialização na sala de aula.

A esse respeito, a professora Ecy destaca que a finalidade do currículo é nortear o trabalho docente. Conceição concorda e complementa que a realidade da disciplina que ministra (Matemática) é muito difícil e, nesse contexto, o currículo serve apenas para ter ciência do que ministrará, pois sabe que o aluno não vai alcançá-lo. Percebemos um pessimismo na fala da docente e acreditamos que isso esteja relacionado, em parte, ao sentido limitado que ela atribui ao currículo, conforme foi destacado anteriormente. Para refletir esse posicionamento, recorremos a Carmo, Selles e Esteves (2015, p. 100) ao argumentarem que "[...] o que se encontra previsto no currículo, ou pelo menos o que se espera que ocorra na ação, muitas vezes, não corresponde ao que os professores encontram na sala de aula para pô-lo em prática". Nesse sentido, consideramos que situações dessa natureza podem frustrar os docentes, ocasionando questionamentos sobre a própria prática em busca de uma possível explicação para os problemas encontrados. Desse modo, notamos uma tensão no relato da docente, motivado pela dificuldade de materializar o currículo (prescrito) em função de vários problemas vivenciados durante o desenvolvimento curricular.

Aprofundando a reflexão sobre a finalidade do currículo no processo educativo, analisamos, especificamente, os seus objetivos para o Ensino Médio. Consideramos essa discussão relevante porque tem sido cada vez mais atual o debate em torno dos objetivos do ensino. Observamos, portanto, a existência de diferentes finalidades atribuídas ao currículo, nesse processo formativo, por isso, acreditamos que seja um terreno fértil para discutir a questão curricular na perspectiva docente, principal mediador entre o currículo e o conhecimento e a quem é dada, primariamente, a responsabilidade pelo cumprimento da função educativa da escola. 
Desse modo, os sentidos analisados nos relatos revelam que a maioria das entrevistadas considera a educação para vida como a principal função do currículo. Para a professora Telma, a escola precisa formar para a vida porque o trabalho faz parte da vida, mas ele não é a vida. "O homem é muito mais que um trabalhador [...] e o aluno precisa de estímulo para que produza novos conhecimentos. Não acredito em um currículo completamente voltado para o trabalho". Depreendemos desse depoimento o sentido de que a finalidade do currículo é mais profunda e complexa do que apenas a instrumentalização para o trabalho. Já que, como afirma Goodson (2013), o currículo é um instrumento que produz determinadas identidades e subjetividades sociais, pois ele não apenas representa, ele faz. $\mathrm{O}$ autor enfatiza a necessidade de reconhecer que a inclusão ou exclusão no currículo tem conexões com a inclusão ou exclusão na própria sociedade. $\mathrm{Na}$ mesma direção do que afirma Telma, as professoras Ecy e Suely defendem que o aluno precisa ser preparado para a vida porque, desse modo, ele estará capacitado para fazer suas escolhas.

Opostamente aos sentidos apresentados pelas outras entrevistadas, a professora Conceição acredita que o currículo não tem auxiliado na preparação do educando e destaca que "[...] existe uma falha nessa questão do Ensino Médio, preparar para quê? Porque, na verdade, não está preparando para nada [...]". Entendemos que esse sentido denota insatisfação com relação à forma como ocorre o ensino na escola pública, pois a docente faz até um comparativo com a escola privada e questiona “[...] por que lá as coisas funcionam?", além de estar articulado ao conceito de currículo como algo limitado, manifestado pela entrevistada.

Outro sentido percebido nos discursos das professoras apontou uma estreita relação do currículo com a preparação para as avaliações externas. No Brasil, a avaliação externa da educação básica tem ocorrido há mais de 30 anos, envolve escolas e sistemas de ensino e é um tema bastante presente nas discussões entre pesquisadores, dirigentes educacionais e professores (HORTA NETO, 2010).

Sobre esse aspecto, a professora Suely acredita ser importante pensar nas avaliações, porém, admite que isso acaba influenciando suas escolhas ao selecionar conteúdos e metodologias que serão trabalhados nas aulas. Apesar de considerar que a formação para a vida deve ser o objetivo do currículo, em seu relato ela explica que, muitas vezes, acaba tendo que priorizar conteúdos cobrados no Enem e no vestibular porque "[...] a escola está cobrando muito [por meio das] avaliações externas. Então, às vezes, você não tem como fugir disso, tem que se adaptar às exigências atuais”. Esse depoimento evidencia que, devido ao peso dessas avaliações, os docentes acabam priorizando conteúdos que são cobrados em tais exames. Desse modo, corre-se o risco de "[...] as avaliações condicionarem os currículos, fazendo com que a escola e principalmente os professores percam sua autonomia para definir quais os 
conteúdos e as abordagens que seriam mais adequados aos seus alunos, dentro do contexto social em que vivem" (HORTA NETO, 2010, p. 87).

Assim, vale salientar que, segundo Sacristán (2013), o campo do currículo é um território controverso e conflituoso, no qual muitas decisões e escolhas são feitas em conformidade com algumas orientações que não são as únicas possíveis. No caso das avaliações, os relatos demonstram que há uma pressão que faz com que o processo educativo gire em torno delas, priorizando os conteúdos que são exigidos nos exames, demonstrando, assim, a relação de poder que permeia o campo do currículo. Esses resultados revelam o que estudiosos do campo, como Apple (2006), já discutiu a respeito das relações de poder que permeiam a questão curricular, não só na escola, mas também fora dela. Segundo o autor, essas relações evidenciam os responsáveis pelas decisões que envolvem o currículo, portanto, quem detém o poder na sociedade. Tais relações de poder se dão de forma arbitrária e, muitas vezes, o professor é excluído das discussões e decisões curriculares e, assim, o currículo é imposto aos docentes, gerando desconforto e insatisfação.

Na mesma direção, as professoras Conceição e Ecy comentam que o trabalho com Ensino Médio, sobretudo no terceiro ano, acaba sendo voltado para o Enem e para o vestibular. Já a professora Telma reconhece que, de fato, as avaliações externas exercem uma pressão muito grande sob o trabalho do professor e a escola precisa lidar com elas o tempo inteiro. Porém, ela defende que "[...] a escola não pode ficar refém da avaliação externa, precisa ocupar seu lugar, o protagonismo que ela tem nesse processo de discussão daquilo que é relevante, daquilo que é importante ser tratado [...]". Nesse contexto, vale considerar que não é possível que todo o trabalho de uma instituição educativa possa se limitar à aprovação em exames, uma vez que o papel da escola na construção do futuro da sociedade tem uma dimensão muito maior do que os números revelados nas avaliações externas.

A esse respeito, a professora Telma admite que, no atual cenário educativo, o acesso à universidade ocorre, em grande parte, por meio do Enem. Portanto, fica claro que ele abre portas para que o aluno alcance outro nível, isso é importante e precisa ser feito pela escola, mas o papel primeiro dela não é preparar para os exames, mas aguçar o pensamento crítico dos alunos. Por este motivo, a docente julga imprescindível ter espaço para poder discutir aquilo que está sendo ensinado, por que está sendo ensinado, os objetivos e finalidades da escola.

Diante das narrativas, é perceptível que a avaliação externa é um fator de grande influência no desenvolvimento do currículo, induzindo, significativamente, o trabalho docente, pois acaba impondo determinadas escolhas e atitudes ao professor no exercício da sua prática. Entendemos também que o foco, apenas, nas avaliações externas, acaba limitando o processo formativo do aluno, pois são priorizados conhecimentos cobrados nas provas. De acordo com

v.9
n. 2 p. $259-274$ maio/ago. 2018 eISSN 2178-8359 
Cunha (2016), muitos estudos evidenciam que o crescimento das avaliações externas tem afetado a gestão do currículo nas escolas, porquanto tem feito com que secretarias de estados e de municípios façam das matrizes de avaliação das provas o próprio currículo.

No âmbito dessas discussões, Sacristán (1998c, p. 320) destaca o fato de que, a ênfase nos resultados das avaliações pode comprometer os debates e análises acerca da real situação educacional. Além disso, "[...] submete os professores a uma pressão externa, 'subtraindolhes a autonomia profissional' e impedindo-os, contraditoriamente, de desenvolver um trabalho mais profícuo com seus alunos". Para o autor, o que "[...] a avaliação externa faz é destacar o valor seletivo e social da mesma, ao tempo em que deforma as possibilidades do currículo. A prática do ensino-aprendizagem vai ficar muito marcada pela urgência em superar as provas seletivas" (SACRISTÁN, 1998c, p. 321).

Desse modo, defendemos que esta é uma discussão que precisa ser feita não só pelos profissionais da educação, mas por toda a sociedade, em função dos novos rumos dados ao Ensino Médio, a exemplo da Medida Provisória no 746/2016, que impõe significativas mudanças na educação nacional, e da Base Nacional Comum Curricular, que define o conteúdo que os alunos deverão aprender em cada etapa de ensino.

Enfim, a apreciação do cenário atual aponta para muitas mudanças no campo educativo, a maioria delas com foco no currículo. De modo especial, temos no centro das discussões dois elementos essenciais: os conteúdos - o que os educandos devem saber; e, os objetivos - o que os educandos devem ser. Esses são aspectos profundamente interdependentes do currículo que, devido a sua importância no processo educativo, são objetos de estudo de inúmeras pesquisas.

Em síntese, os relatos apontaram a educação para a vida como a principal finalidade do currículo, porém, chamou-nos a atenção o fato de as avaliações externas estarem influenciando diretamente o trabalho das docentes, até determinando o que deve ou não ser abordado na escola. É nítida nos relatos das docentes a pressão a que estão submetidas ao ter que cumprir um currículo que, prioritariamente, prepara para as avaliações externas, sem que existam condições adequadas de trabalho. Com isso, cria-se um distanciamento entre o currículo previsto e aquele que realmente é cumprido - o currículo vivido. Esse descompasso ocorre em função de vários fatores que, por vezes, limitam e comprometem o trabalho do professor.

Portanto, vale ressaltar que a complexidade do contexto escolar requer clareza dos professores quanto às finalidades do currículo no processo educativo e discernimento para operacionalizar os objetos de ensino, tendo em vista que os desafios são inerentes ao universo educativo. É justamente por isso que o currículo precisa ser entendido como um dispositivo

\begin{tabular}{l|c|c|c|c|c|c} 
(C) Rev. Educ. Perspec. & Viçosa, $M G$ & v.9 & n.2 & p.259-274 & maio/ago. 2018 & eISSN 2178-8359 \\
\hline
\end{tabular}


capaz de auxiliar o desenvolvimento do trabalho docente, já que sua finalidade no processo educativo vai muito além do que determinar o que será ensinado. Afinal, o currículo envolve toda a ação docente e é por meio dele que os objetivos da escola se concretizam na sala de aula.

\section{PAPEL DO PROFESSOR NO DESENVOLVIMENTO DO CURRÍCULO}

Esta última categoria discute o papel docente no desenvolvimento curricular. Consideramos importante destacar este aspecto porque o docente é um dos principais responsáveis por promover o processo de aprendizagem. Além disso, é um dos grandes artífices no processo que envolve a materialização do currículo na sala de aula (MOREIRA; CANDAU, 2007), portanto, sua atuação é determinante no processo de escolarização, pois o desenvolvimento do currículo implica fazer escolhas, renúncias, decidir entre opções que não são exclusivas, mas que podem impactar significativamente o aprendizado do aluno.

Em consonância, Flores e Flores (1998) ressaltam que, devido à expansão nos estudos do currículo, muitos pesquisadores passaram a admitir que o docente não pode ser um mero aplicador de diretrizes. Além disso, os autores destacam que as pesquisas acerca do pensamento do professor são fundamentais, pois demonstram que, para a compreensão da prática docente, é necessário saber o que ele pensa, com isso, o professor passou a ser considerado como mediador curricular e intérprete dinâmico da prática educativa.

Nessa perspectiva, vale enfatizar que o processo pelo qual o currículo passa da esfera técnicopolítica à prático-pedagógica exige a mediação docente, pois o que é ensinado na sala de aula "[...] é o resultado de um processo de decodificação, interpretação, significação, recriação, reinterpretação de ideias, condições e práticas disponíveis na cultura, que se tornam mais ou menos visíveis e viáveis em um contexto situacional de interação e intercâmbio de significados" (ACOSTA, 2013, p. 189). E todo esse processo depende, fundamentalmente, dos sentidos atribuídos pelo educador à escola, à educação, à avaliação, ao currículo etc.

Depreendemos do relato da professora Ecy, o sentido de que o papel docente no desenvolvimento do currículo é primordial uma vez que "[...] o professor é o detentor do conhecimento, [...] o mediador que vai fazer a ponte para que essa abertura aconteça [...] mostrar os caminhos, abrir os espaços, criar oportunidades para o aluno se inserir". Assim como a professora, reafirmamos que o educador tem um papel central na mediação entre o currículo e o aluno. Afinal, como ressalta Sacristán (2000), o professor, visto simplesmente como quem aplica o currículo, não corresponde à sua função educativa, pois ele é um agente ativo no seu desenvolvimento. É quem pode organizar o currículo de acordo com as 
necessidades formativas dos alunos, em sintonia com as suas demandas pessoais e socioculturais.

Diante disso, importa destacar a relevância da atuação do professor como um mediador curricular, já que, muitas vezes, ele é visto apenas como um executor de propostas elaboradas por outras pessoas, secundarizando sua atuação no desenvolvimento do currículo. A esse respeito, Sacristán (2000) assevera que o professor é um mediador decisivo entre o currículo estabelecido e os alunos. Ele é o principal agente responsável por concretizar o projeto curricular por meio dos objetivos propostos pela escola. Portanto, a atuação docente está longe de ser apenas reprodutora, uma vez que é por meio da prática que o currículo se materializa na escola.

No entendimento da professora Telma, o professor tem um papel fundamental, porquanto é quem faz a releitura da realidade da turma, daquilo que os alunos precisam aprender, articulando real e ideal, fazendo o movimento de tencionar a necessidade do aluno e aquilo que ele precisa aprender, interpretando a realidade na qual está inserido. Compreendemos que é com base na sua experiência e mediante essa interpretação que a docente planeja o que será realizado em sua aula. Por conseguinte, o papel do professor no desenvolvimento do currículo abarca a permanente tomada de decisões que terão incidência direta no processo de ensino e aprendizagem (CUNHA, 2005). Logo, não é uma tarefa tão simples, e as escolhas feitas pelos professores são dependentes dos significados por eles atribuídos, uma vez que é com base em seus mundos de sentidos que interpretam e desenvolvem o currículo. Nesse contexto, recorremos a Sacristán (2000) para enfatizar quão complexa é essa mediação pelo professor, não devendo ser vista como uma simples operação de retirar ou acrescentar, já que, diariamente, o professor tem que enfrentar situações singulares, improváveis e conflitivas ao abordar os conteúdos curriculares.

No entanto, apesar de o exercício da docência exigir, regularmente, decidir entre várias alternativas possíveis no desenvolvimento curricular, Thiesen (2012) explica que muitos educadores acabam reduzindo sua atuação a de meros consumidores de prescrições curriculares. Tal situação ocorre, ressalta o autor, devido às limitações impostas à carreira, privando-os da participação nos debates acerca da questão curricular. Desse modo, Elliott (1990 apud MUÑOZ, 2013) defende que os docentes não devem se limitar a consumir o currículo, pelo contrário, devem intervir em seu desenvolvimento de modo que a sua atuação seja coadjuvante dessa intervenção e não mera reprodução.

Para professora Suely, o docente é um dos agentes mais importantes da escola, é um profissional que possui qualificação, é quem conhece a realidade da turma. Portanto, tem condições de atuar de maneira significativa no desenvolvimento do currículo. Contudo, ela explica que a atuação docente fica limitada à forma de materializar as prescrições, de modo

\begin{tabular}{l|c|c|c|c|c|c|} 
(C) Rev. Educ. Perspec. & Viçosa, $M G$ & v.9 & n.2 & p.259-274 & maio/ago. 2018 & eISSN 2178-8359 \\
\hline
\end{tabular}


que "[...] o papel do professor acaba sendo complementar o currículo porque na matriz comum [...] ele não tem autonomia para fazer alguma modificação, ainda que seja relevante para a escola". Sobre este aspecto, inferimos que, mesmo o professor não tendo autonomia para realizar modificação na proposta curricular da escola, ele é o agente mais importante no seu processo de desenvolvimento, a quem cabe analisar, interpretar e configurar o currículo por meio do planejamento para ser concretizado na sala de aula. Isso significa atuar como um mediador curricular e decidir como será conduzido todo o processo educativo, função docente que não deve ser secundarizada. Ademais, mesmo que não perceba, o educador é o protagonista na gestão do currículo, ainda que seja somente no momento de colocá-lo em ação (SAKAY, 2012).

Na mesma perspectiva, professora Conceição defende que o docente deveria ter autonomia para fazer alterações no currículo. Considera que não pode ser uma coisa engessada, visto que é o instrumento para nortear o trabalho docente, por isso, o professor precisa fazer as adequações de acordo com a realidade de cada turma. Nesses relatos, é possível perceber que a falta de autonomia tem feito com que a participação do professor no desenvolvimento do currículo se restrinja ao planejamento docente, tendo em vista que a proposta curricular é estabelecida previamente e nem sempre o professor participa de sua construção. Tais relatos evidenciam a falta de autonomia como um fator que denuncia conflitos no desenvolvimento do currículo, demonstrando o distanciamento entre o currículo prescrito e o currículo que é materializado no contexto escolar. Entendemos que essa situação contribui para que o papel dos professores se limite a executores das propostas curriculares, não assumindo o lugar de protagonistas que devem ter no desenvolvimento curricular.

Contudo, Sacristán (2000) argumenta que, mesmo a proposta curricular da escola sendo muito controlada, rigidamente estruturada, o professor é o último árbitro de seu desenvolvimento nas aulas. Por isso, a concretização de qualquer currículo passa, necessariamente, pela análise e interpretação do docente. Desse modo, o autor evidencia que os professores podem exercer papéis possíveis e previsíveis frente ao desenvolvimento do currículo: ou aceitam o papel passivo de mero executor, ou decidem atuar como um profissional crítico, que utiliza o conhecimento e a sua autonomia para, em cada situação educativa, ter a oportunidade de desenvolver uma prática docente responsável e comprometida.

Nesse sentido, os relatos evidenciaram um cenário permeado por inúmeros desafios, alguns relacionados, muitas vezes, aos alunos, à direção, aos colegas, às imposições internas e/ou externas, às condições organizacionais e estruturais da escola e até mesmo ao próprio professor. Esse cenário, por vezes, contribui para que o professor se sinta excluído das decisões acerca do currículo e destituído de autonomia para elaborá-lo ou alterá-lo, mesmo sendo o principal responsável por materializá-lo na sala de aula. Esse panorama exige que o 
professor tenha consciência de que tem um papel fundamental no desenvolvimento curricular, pois ele é o mediador decisivo entre o currículo e o aluno. Assim, mesmo conhecendo os limites da atuação profissional, podemos afirmar, com base nos resultados encontrados e em diálogo com estudos de Sacristán (2000), que o docente desempenha um papel ativo ao dar forma ao currículo para materializá-lo na aula.

\section{CONSIDERAÇÕES FINAIS}

Com este estudo foi possível destacar alguns pontos importantes acerca do currículo escolar na perspectiva docente. Observamos que os sentidos atribuídos ao currículo transitam entre dois opostos, ora é visto como uma ferramenta fundamental na prática docente e no processo educativo, ora como algo limitado, tendo, neste último caso, sua relevância reduzida. Acreditamos que essa polaridade de sentidos é resultado da interpretação pessoal da realidade que cada docente construiu por meio das suas experiências, uma vez que a trajetória individual de cada professora colabora para que tenham visões distintas do currículo, mesmo estando inseridas no mesmo contexto escolar, compartilhando dificuldades que, em alguns pontos, se assemelham. No entanto, a falta de condições adequadas para o desenvolvimento da atividade docente também fortalece a visão do currículo como algo negativo.

Notamos, ainda, a existência de diferentes finalidades atribuídas pelas professoras ao currículo, como educar para a vida, preparar para as avaliações externas e capacitar para o mercado de trabalho. Contudo, chamou-nos a atenção a influência das avaliações externas no desenvolvimento do trabalho docente, muitas vezes, definindo o que deverá ser abordado, cerceando, assim, a autonomia do professor. Nesse sentido, fundamentados nos dados produzidos, inferimos que o objetivo do currículo deixou de ser a formação para a vida, priorizando, sobretudo, a preparação para os exames e, assim, restringindo e limitando o processo formativo do aluno.

Ademais, apresentamos os sentidos que as professoras atribuem ao papel docente no desenvolvimento curricular, o que permitiu destacar que o professor é visto como um mediador decisivo entre o currículo e os alunos, um agente fundamental no processo de construção curricular. Nessa perspectiva, o docente apresenta-se como personagem principal no campo curricular, cuja atuação tem implicações para o processo de escolarização, uma vez que o currículo traduz os objetivos da instituição escolar, ao mesmo tempo em que é o configurador de toda a prática pedagógica.

Considerando que os sentidos atribuídos pelas professoras ao currículo e sua finalidade no processo educativo têm forte relação com aquilo que se concretiza na sala de aula, julgamos imprescindível destacar a importância do papel docente nesse processo. Entendemos que o

(C) Rev. Educ. Perspec.

n.2 1 p.259-274

eISSN 2178-8359


professor é um dos principais agentes no desenvolvimento do currículo, pois ele é o último tradutor da proposta curricular da escola que, após ser interpretada, será retraduzida em ações concretas, contribuindo para a construção do conhecimento pelos alunos. Esse pensamento denota o poder do docente que se materializa ao planejar sua prática e evidencia a importância do estudo do planejamento curricular a partir da perspectiva docente. Desse modo, destacamos a importância de estudos que possam investigar como o professor planeja as ações pedagógicas, procurando compreender as razões que fundamentam suas escolhas.

\section{REFERÊNCIAS}

ACOSTA, Javier Marrero. O currículo interpretado: o que as escolas, os professores e as professoras ensinam? In: SACRISTÁN, José Gimeno (Org.). Saberes e incertezas sobre o currículo. Porto Alegre: Penso, 2013. P. 188-207.

ALBINO, Ângela Cristina, PEREIRA, Maria Zuleide da Costa, LIMA, Idelsuite de Sousa. Currículo: (re)construindo sentidos de educação e ensino. Espaço do Currículo, v. 7, n. 1, p. 5-12, jan./abr. 2014. Disponível em:

<http://www.periodicos.ufpb.br/index.php/rec/article/view/19419/0>. Acesso em: 04 maio 2018.

APPLE, Michael Whitman. Ideologia e currículo. 3. ed. Porto Alegre: Artmed, 2006.

BARG, Gilmar. O currículo da rede municipal de ensino de Blumenau/SC no período de 1997 a 2004: uma abordagem baseada nos estudos pós-coloniais. 2012. 181f. Dissertação (Mestrado em Educação). Programa de Pós-graduação em Educação. Universidade Regional de Blumenau - FURB, Blumenau, 2012.

CARMO, Edinaldo Medeiros; SELLES, Sandra Escovedo; ESTEVES, Maria Manuela. Concepções de professores de Biologia sobre a profissão docente. Educação, Sociedade \& Culturas, Porto, PT, v. 44, p. 87-106, 2015. Disponível em:

<http://www.fpce.up.pt/ciie/sites/default/files/ESC44_Medeiros.pdf>. Acesso em: 08 set. 2016.

CONTRERAS, José. A autonomia de professores. 2. ed. São Paulo: Cortez, 2002.

CUNHA, Érika Virgílio Rodrigues da. A prática de planejamento curricular de professoras do $1^{\circ}$ ciclo do ensino fundamental no contexto da implantação de ciclos na rede pública municipal de Rondonópolis/MT. 2005. 221f. Dissertação (Mestrado em Educação). Programa de Pós-graduação em Educação. Universidade Federal de Mato Grosso, Cuiabá, 2005. 
CUNHA, Isabela Bilecki. A relação entre o currículo e as avaliações externas: Um estudo sobre a rede municipal de São Paulo. Revista Teias, Rio de Janeiro, v. 17, n. 47, p. 43-58, out./dez. 2016. Disponível em:

<http://www.e-publicacoes.uerj.br/index.php/revistateias/article/view/25900>. Acesso em: 06 jan. 2017.

FLORES, Maria Assunção; FLORES, Manuel. O professor: agente de inovação curricular. In: Colóquio sobre Questões Curriculares, 3. 1998, Braga. Actas. Braga: Centro de Estudos em Educação e Psicologia da Universidade do Minho, p. 79-99, 1998. Disponível em: $<$ https://repositorium.sdum.uminho.pt/bitstream/1822/657/1/MariaAFlores.pdf >. Acesso em: 15 dez. 2016.

GOODSON, Ivor. Currículo, teoria e história. Petrópolis: Vozes, 2013.

HORTA NETO, João Luiz. Avaliação Externa de Escolas e Sistemas: Questões presentes no debate sobre o Tema. Revista Brasileira de Estudos Pedagógicos, Brasília, v. 91, p. 84-104, 2010. Disponível em: <http://rbep.inep.gov.br/index.php/rbep/article/view/604>. Acesso em: 04 jan. 2017.

MALTA, Shirley Cristina Lacerda. Uma abordagem sobre currículo e teorias afins visando à compreensão e mudança. Espaço do Currículo, Paraíba, v. 6, n. 2, p. 340-354. maio/ago. 2013. Disponível em: <periodicos.ufpb.br/index.php/rec/article/download/3732/9757>. Acesso em: 06 nov. 2016.

MOREIRA, Antônio Flávio Barbosa. Currículo: políticas e práticas. 13. ed. Campinas: Papirus, 2013. P. 165-183.

MOREIRA, Antônio Flávio Barbosa. Currículo e conhecimento: aproximações entre educação e ensino. Caderno de Pesquisa, São Paulo. v. 42, n. 147, p. 716-737, 2012. Disponível em: www.scielo.br/scielo.php?pid=S0100-15742012000300004\&script= sci_abstract\&tlng=pt. Acesso em: 15 maio 2018.

MOREIRA, Antônio Flávio Barbosa; CANDAU, Vera Maria. Indagações sobre currículo: currículo, conhecimento e cultura. Brasília: Ministério da Educação, Secretaria de Educação Básica, 2007.

MUÑOZ, Francisco Imbernón. A formação dos professores e o desenvolvimento do currículo. In: SACRISTÁN, José Gimeno (Org.). Saberes e incertezas sobre o currículo. Porto Alegre: Penso, 2013. P. 494-507.

SACRISTÁN, José Gimeno. O que significa o currículo? In: SACRISTÁN, José Gimeno (Org.). Saberes e incertezas sobre o currículo. Porto Alegre: Penso, 2013. P. 16-35.

SACRISTÁN, José Gimeno. O currículo: uma reflexão sobre a prática. Porto Alegre: ArtMed, 2000. 
SACRISTÁN, José Gimeno. Plano do currículo, plano do ensino: o papel dos/as professores/as. In: SACRISTÁN, José Gimeno; PÉREZ GÓMEZ, Ángel I. (Org.). Compreender e transformar o ensino. 4. ed. Porto Alegre: Artmed, 1998a. p. 197-223.

SACRISTÁN, José Gimeno. O currículo: os conteúdos do ensino ou uma análise pratica? In: SACRISTÁN, José Gimeno; PÉREZ GÓMEZ, Angel I. (Org.). Compreender e transformar o ensino. 4. ed. Porto Alegre: Artmed, 1998b. P. 119-148.

SACRISTÁN, José Gimeno. A Avaliação no ensino. In: SACRISTÁN, José Gimeno; PÉREZ GÓMEZ, Angel I. (Org.). Compreender e transformar o ensino. 4. ed. Porto Alegre: Artmed, 1998c. P. 295-351.

SAKAY, Lady. Ensino e aprendizagem do número racional positivo na forma decimal: análise de uma experiência de inversão curricular. 2012. 329f. Brasília, Tese (Doutorado em Educação). Faculdade de Educação, Universidade de Brasília, Brasília, 2012.

SILVA, Tomaz Tadeu. Documentos de identidade: uma introdução às teorias do currículo. 2. ed. Belo Horizonte: Autêntica, 1999.

THIESEN, Juarez da Silva. O que há no "entre" teoria curricular, políticas de currículo e escola? Educação, Porto Alegre, v. 35, n. 1, p. 129-136, jan./abr. 2012. Disponível em: http://revistaseletronicas.pucrs.br/fo/ojs/index.php/faced/article/view/7407/7548. Acesso em: 22 dez. 2014.

VASCONCELOS, Celso dos Santos. Para onde vai o professor? Resgate do professor como sujeito de transformação. 12. ed. São Paulo: Libertad, 2007.

\section{NOTAS}

${ }^{1}$ Com a finalidade de manter o anonimato das professoras, optamos por identificá-las com nomes fictícios.

\section{Sobre os Autores}

${ }^{1}$ Maria Narleide Oliveira Castro - Mestre em Educação pela Universidade Estadual do Sudoeste da Bahia - E-mail: naycastro15@gmail.com - ORCID: https://orcid.org/0000-0003-4399-0860

${ }^{2}$ Edinaldo Medeiros Carmo - Doutor em Educação. Professor Adjunto do Departamento de Ciências Naturais da Universidade Estadual do Sudoeste da Bahia - E-mail: medeirosed@uesb.edu.br ORCID https://orcid.org/0000-0002-1594-8983 